\title{
Neonatal Nonhandling and In Utero Prenatal Stress Reduce the Density of NADPH-Diaphorase-Reactive Neurons in the Fascia Dentata and Ammon's Horn of Rats
}

\author{
R. R. Vaid, ${ }^{1}$ B. K. Yee, ${ }^{2}$ U. Shalev, ${ }^{3}$ J. N. P. Rawlins, ${ }^{2}$ I. Weiner, ${ }^{3}$ J. Feldon, ${ }^{3}$ and S. Totterdell ${ }^{1}$ \\ ${ }^{1}$ Department of Pharmacology, University of Oxford, Oxford OX1 3QT, England, '2Department of Experimental Psychology, \\ University of Oxford, Oxford OX1 3UD, England, and 'Department of Psychology, Tel-Aviv University, Ramat-Aviv, \\ Tel-Aviv, Israel 69978
}

\begin{abstract}
The density of nitric oxide (NO)-producing neurons in the fascia dentata and Ammon's horn was assessed in 6-month-old male rats using NADPH-diaphorase (NADPH-d) histochemistry. Two separate experiments investigated whether (1) the complete absence of neonatal handling or (2) the administration of periodic prenatal stress could affect the expression and distribution of NADPH-d reactivity in the hippocampus, when compared with rats raised in normal standard laboratory conditions. Experiment 1 demonstrated that adult rats that received no handling during neonatal development (from birth to postnatal day 22) showed a very substantial reduction in NADPH-d-positive neurons per unit area throughout the entire hippocampus when compared with rats that received regular daily handling in this period. Quantitative analysis further revealed that this effect was significantly more pronounced in Ammon's horn than in the
\end{abstract}

fascia dentata, and within Ammon's horn the dorsal region was selectively more affected. Experiment 2 showed that prenatal stress, which involved the administration of daily restraint stress to pregnant dams throughout the gestation period, also led to a reduction in NADPH-d reactivity in the hippocampus of the offspring of these dam when they reached adulthood.

The present results suggest that behavioral manipulations in the early neonatal or prenatal period can significantly alter the neurodevelopment of the hippocampal NO system and these changes might be related to some of the behavioral abnormalities that emerge later in adulthood.

Key words: nitric oxide; NADPH-diaphorase; hippocampus; hypothalamo-pituitary-adrenal axis; stress; postnatal stimulation; rat
There is considerable evidence to suggest that the hippocampus undergoes postnatal neurogenesis. This has been observed in various species (mouse: Angevine, 1965; monkey: Rakic and Nowakowski, 1981; rat: Altman and Das, 1965; cat: Purpura and Pappas, 1968), including human. On the basis of their analysis of the Yakovlev collection, Kretschmann et al. (1986) concluded that the maximum rate of growth of the human hippocampal formation occurs at approximately 2 months postnatally. Myelination of the human hippocampal formation does not reach adult levels until 3-5 years after birth (Brody et al., 1987), and significant myelination of the extra subicular cortices can still be detected in adolescence and early adulthood (Benes et al., 1994). Similarly, cellular content of RNA in the subicular cortices does not attain adult levels until the ninth year of life (Uemura and Hartmann, 1979). Thus, there are prolonged periods of early life during which significant maturation occurs in the human hippocampal formation and adjacent cortical areas.

It is well known that ontogeny is constantly under the guidance of factors both internal and external to the organism. Early

\footnotetext{
Received April 15, 1997; accepted April 29, 1997.

This study was supported by Bristol Myers Squibb. R.R.V. also received additional support from the McDonnell-Pew Foundation and was the recipient of an Overseas Research Studentship Award (British government funded). We thank Professor David Smith for his support in this study.

Correspondence should be addressed to Dr. S. Totterdell, University Department of Pharmacology, Mansfield Road, Oxford OX1 3QT, England.

Dr. Feldon's present address: Laboratory of Behavioral Biology and Functional Toxicology, Institute of Toxicology, The Swiss Federal Institute of TechnologyZürich, Schorenstrasse 16, CH-8603 Schwerzenbach, Switzerland.

Copyright (C) 1997 Society for Neuroscience $0270-6474 / 97 / 175599-11 \$ 05.00 / 0$
}

experience is one such factor that often only leads to observable divergence in behavioral adaptation later in adulthood. The prolonged period of neurodevelopment of the hippocampus and related cortical structures suggests that the development of these areas may be particularly sensitive to the influence of such factors in early life. These are therefore candidate structures related to the mechanism(s) underlying the relationship between early experiences and specific phenotypic traits in adulthood.

In the rat, two forms of early environmental/behavioral manipulations have been investigated extensively. One of these is neonatal nonhandling, which compares animals raised in the complete absence of handling during neonatal period to control (i.e., handled) animals that typically are removed briefly from their mothers daily between birth and weaning (postnatal day 22). The other is prenatal stress, which involves the periodic administration of mild restraint stress to the pregnant mother throughout the gestation period. Both of these procedures have been reported to produce behavioral abnormalities later in adulthood. Prenatal stress has been reported to alter fear-motivated and defensive behavior (Thompson, 1957; Archer and Blackman 1971), to enhance amphetamine-induced locomotor activity as well as amphetamine self-administration (Deminière et al., 1992), and to increase signs of anxiety (Fride and Weinstock, 1988; Wakshlak and Weinstock, 1990). On the other hand, neonatal stimulation has a number of clear behavioral effects in adulthood (Meaney et al., 1989) that include enhanced exploratory behavior and an attenuation of novelty-induced anxiety (Levine, 1957, 1962; Levine et al., 1967; Ader and Grota, 1969; Hess et al., 1969). In contrast, sensory deprivation during early development is 
associated with abnormal emotional behavior in later life (Melzack and Thompson, 1956).

It is believed that the physiological mechanisms underlying the behavioral changes that emerge in adulthood, associated with early manipulations of this kind, are related to dysfunction of the hypothalamic-pituitary-adrenal (HPA) axis and/or its regulation by a glucocorticoid (GC) feedback mechanism, especially under stressful situations, such as normal environmental stress, as well as discrete experimental stressors (Sapolsky et al., 1984; Meaney et al., 1988, 1989). It has been reported that rats raised in the complete absence of handling during the neonatal period showed a higher corticosterone response to stress and recovered from stress more slowly, i.e., showed a slower corticosterone return to baseline level, in comparison with handled rats. Thus, it seems that nonhandled rats are less adaptable to stress (Levine, 1957, 1962; Ader and Grota, 1969; Hess et al., 1969). Consistent with this view, nonhandled rats also show a more fearful response to novelty and a more pronounced increase in adrenal GC response after presentation of various experimental stressors. Similarly, rats that were prenatally stressed showed persistent elevation of plasma corticosterone in response to repeated stress induced by novel stimuli (Fride et al., 1986). This suggests that prenatally stressed animals may suffer from an endocrine abnormality similar to that in nonhandled animals.

The hippocampus is known to contain both type I and type II GC receptors, which are critical to the GC homeostatic regulation of the HPA axis mentioned above. There is evidence to suggest that the hippocampus undergoes neuroanatomical changes that may be related to the dysfunction of the HPA axis in neonatally nonhandled rats and prenatally stressed rats. Most notably, nonhandled rats exhibit less type II, but not less type I, GC receptor binding in the hippocampus. This reduction was likely to be attributed to changes in postnatal developmental processes. Furthermore, this effect was specific to the hippocampus; it was not detected in the septum, amygdala, hypothalamus, or pituitary gland (Meaney and Aitken, 1985; Meaney et al., 1985a,b, 1987, 1989, 1992, 1993a,b). LaRocque et al., (1992) have also observed that glucocorticoid type II receptor mRNA expression is lower in the hippocampus of nonhandled rats. Developmentally, hippocampal type II receptor binding capacity is low during the first week of life and then increases, approaching adult levels $\sim 3$ weeks after birth, whereas the density of type I hippocampal GC receptors is already close to the adult level early in postnatal life (Sarrieau et al., 1988). These reports strongly suggest that the complete absence of neonatal handling may arrest the development of the type II GC receptor system in the still developing hippocampus. Thus, adult rats raised without any neonatal handling, like immature rats, are characterized by low concentrations of hippocampal GC receptors, and consequently an insensitivity to GC feedback inhibition. This in turn would lead to an impaired ability to terminate a corticosterone response to normal environmental stress as well as discrete experimental stress later in adulthood (Levine, 1957, 1962; Ader and Grota, 1969; Hess et al., 1969).

Recently, it has been reported that GC can inhibit mRNA synthesis of nitric oxide synthase (NOS) via receptor-mediated processes (Radomski et al., 1990). In agreement with this, Weber et al. (1994) also reported that corticosterone negatively modulates NOS gene expression in the hippocampus. Because neonatal nonhandling and prenatal stress can lead to prolonged elevation of GC levels in response to experimental stress later in adult life, it is conceivable that these procedures may also affect the devel- opment of the NO system in the brain, and the hippocampus in particular. The present study was designed to test the hypothesis that these early behavioral manipulations may reduce the density of NO-producing neurons in the hippocampus. It did not provide a direct test for a possible causal relationship between an elevated corticosterone stress response and the neurodevelopment of the hippocampal NO system. Nevertheless, if neither or only one of these manipulations affects the NO system in the predicted direction, then it would undermine the suggestion of a causal link between the enhanced corticosterone stress response associated with both of these manipulations in later adult life and the neurodevelopment of the NO system in the hippocampus.

The present study used NADPH-diaphorase (NADPH-d) histochemistry, a staining technique that has been widely used as a potential marker for NO-producing neurons, in both fixed and unfixed tissue (e.g., Bredt et al., 1991; Pasqualotto et al., 1991; Vincent and Kimura, 1992), although the sensitivity of NADPH-d histochemistry toward cells containing different isoforms of NOS may vary (Bredt et al., 1991; Dawson et al., 1991; Hope et al., 1991, Schmidt et al., 1992; Dun et al., 1994). The first of the two experiments reported here compared the density of NADPH-d-reactive hippocampal neurons in adult male rats (6 months old) raised without neonatal handling with that in rats that received regular handling when they were neonates. The second experiment was an identical analysis in adult male rats whose dams had been stressed throughout gestation, compared with control rats born to unstressed dams. Quantitative analyses were carried out in both experiments to examine whether these early behavioral manipulations would affect the relative density of these neurons along the three hippocampal axes: at three septotemporal levels, in different hippocampal subfields (fascia dentata, CA2/3, and CA1), and among different cell layers (or strata) within each subfield.

\section{MATERIALS AND METHODS}

\section{Experiment 1}

Subjects and the administration of neonatal handling/nonhandling. Adult female Wistar rats (obtained from Tel-Aviv University Medical School) were mated. At $\sim 15 \mathrm{~d}$ before giving birth, the pregnant rats were housed individually in opaque plastic holding cages, $35 \times 29 \times 16 \mathrm{~cm}$ in size. The floors of the cages were covered with sawdust bedding. On the day after birth, all litters were randomly culled to a size of eight each. Half of the litters were randomly assigned to the handled condition, the other half were assigned to the nonhandled condition. All animals were housed under a $12 \mathrm{hr}$ reversed light/dark cycle. The handling procedure, as specified below, was always performed in the dark phase of the cycle.

On the third day after birth, daily handling was administered to the litters born to mothers belonging to the handled group. This was continued daily for $20 \mathrm{~d}$, until weaning at postnatal day 22 . The handling procedure began by removing the mother from the pups and placing her into a separate holding cage until the end of the handling procedure. Each pup was then placed individually into a small cardboard box, $5 \times$ $5 \times 5 \mathrm{~cm}$, containing sawdust bedding identical to that used in their home cage. They were left in the cardboard boxes undisturbed for $3 \mathrm{~min}$. The pups and the mother were then returned to the home cage.

Mothers and pups of the nonhandled group were left entirely undisturbed until weaning on postnatal day 22. These pups were never handled during this period. It is important to note that it is not a standard laboratory practice to avoid handling completely during this period. Handling of pups is common in rat breeding colonies during the neonatal period, either for the purpose of cage cleaning or for changing the bedding (Greenberg and Bursdal, 1982). For experimental purposes, the handling procedure had to be explicitly standardized. Thus it was the nonhandling group that constituted the critical experimental manipulation (Levine, 1960).

At weaning, offspring of the same sex were rehoused two to four to a cage. Animals in the handled group were caged separately from those in 
the nonhandled group. Apart from this, the animals were treated in the same way from this point onward. Three male rats, each randomly selected from a different litter in the handled group, and three male rats randomly chosen from a separate litter in the nonhandled group were used in Experiment 1. They were killed by perfusion as described below when they reached 6 months of age.

\section{Experiment 2}

Subjects and the administration of prenatal immobilization stress. Adult female Wistar rats (obtained from Tel-Aviv University Medical School) were mated. Mild restraint stress was administered daily throughout the entire gestation period to half of the pregnant females. This consisted of placing the rats individually inside a transparent Plexiglas cylinder, $5 \mathrm{~cm}$ inner diameter and $16 \mathrm{~cm}$ long. They were left in the restraint tube, which was placed horizontally on a table located in a separate room, for a period of $30 \mathrm{~min}$ per day. Afterward, they were returned to their home cage undisturbed. Control animals were left undisturbed throughout pregnancy. All pregnant rats were caged singly under a $12 \mathrm{hr}$ reversed light/dark cycle, lights on at 7 P.M. Prenatal stress was always administered in the dark phase of the cycle.

After birth, litters from both stressed and nonstressed dams were randomly culled to a size of eight each and were kept under identical normal laboratory rearing conditions until $21-23 \mathrm{~d}$ of age, when they were weaned and transferred to colony cages in groups of four consisting of male rats only. Throughout the postnatal period, the animals were kept in the same animal-keeping room and were directly handled only during routine change of cage bedding twice a week. Indirect human contact, such as refilling of food hoppers and water bottles, was identical to standard laboratory practice.

A total of four prenatally stressed male rats (each randomly selected from a separate litter) and four control male rats (each also randomly selected from a separate litter) were selected for Experiment 2. These animals were killed by perfusion at the age of 6 months.

\section{Perfusion and histological processing}

Animals from the same experiment were perfused on the same day, so that their brains could be sectioned and processed together under identical conditions.

The animals were deeply anesthetized with a chloral hydrate barbiturate mixture $(3 \mathrm{ml} / \mathrm{kg}$, i.p., containing $42 \mathrm{mg} / \mathrm{ml}$ chloral hydrate and 9.7 $\mathrm{mg} / \mathrm{ml} \mathrm{Nembutal}$ ) and perfused transcardially at a flow rate of $20 \mathrm{ml} / \mathrm{min}$. They were initially perfused with $0.9 \%$ saline for $2-3 \mathrm{~min}$, followed by a fixative mixture of $4 \%$ paraformaldehyde and $0.1 \%$ glutaraldehyde in 0.1 $\mathrm{M}$ phosphate buffer, $\mathrm{pH} 7.4$, for $15 \mathrm{~min}$. The brains were then removed in toto and stored in $0.1 \mathrm{M}$ phosphate buffer for $48 \mathrm{hr}$ at $4^{\circ} \mathrm{C}$ before they were sectioned. At this stage, the grouping of each brain was coded (in Tel-Aviv), so that the experimenter (in Oxford) was blind to the source of each brain throughout histological processing and during subsequent histomorphometric examination.

All brains were sectioned in the horizontal plane using a vibrating microtome (Vibroslice, Polaron, Hemel Hempstead, UK) into $70 \mu \mathrm{m}$ sections. One in every six sections was collected for NADPH-d histochemistry. An additional series of sections was collected for cell body visualization using conventional cresyl violet stain.

\section{NADPH-d histochemistry}

In both experiments, NADPH-d activity was visualized using a procedure based on that described by Hope and Vincent (1989). All six brains from Experiment 1 were processed at the same time, under identical conditions. Similarly, the eight brains from Experiment 2 were also processed together. Free-floating sections were incubated at $37^{\circ} \mathrm{C}$ in a 50 $\mathrm{mm}$ Tris solution, $\mathrm{pH} 7.4$, containing $0.5 \%$ Triton $\mathrm{X}-100,1 \mathrm{mg} / \mathrm{ml}$ $\beta$-NADPH, reduced form $(\beta$-NADPH), and $0.25 \mathrm{mg} / \mathrm{ml}$ nitro blue tetrazolium. All reagents were obtained from Sigma (Poole, UK).

Sections were inspected periodically under a dissecting microscope at 15 min intervals. The reaction was terminated by washing in cold $50 \mathrm{mM}$ Tris, $\mathrm{pH} 7.4$, when there was no readily appreciable increase in depth of staining between successive inspections. The required reaction time was typically $\sim 2 \mathrm{hr}$. Sections were then mounted onto gelatin-coated slides and allowed to air-dry for $48 \mathrm{hr}$ before being dehydrated in a graded series of alcohol. Afterward, the slides were immersed in xylene before they were coverslipped using XAM mountant.

\section{Histomorphometric evaluation}

The left hemisphere of each subject was used for histomorphometric evaluation in both experiments. Neuronal density (i.e., the number of NADPH-d-reactive cells per $\mathrm{mm}^{2}$ of a defined brain region) was determined using a computerized image analysis system (Seescan) connected to a CCD video camera module (XC-77CE; Sony, Tokyo, Japan) that was attached to a Leica (Wetzlar, Germany) light microscope. NADPH-dreactive neurons were readily recognized by the blue reaction product in cell bodies and processes. A neuron was considered to be positive if and only if the reaction product could be unequivocally identified in the cell soma.

Three horizontal sections corresponding to plates 96, 100, and 105 of the rat brain atlas of Paxinos and Watson (1986) were chosen from each animal. These sections corresponded to the ventral, flexure, and dorsal region of the hippocampal formation, respectively. Before any neuronal density measurement, the surface area of the hippocampus was estimated. This allowed us to assess whether there was any significant volumetric change in the hippocampus (Ammon's horn and fascia dentata) that would affect the interpretation of any neuronal density estimates obtained in this region.

Each section was divided into four subregions along the transverse axis for histomorphometric evaluation. The fascia dentata was subdivided into two divisions or blades. The blade next to the hippocampal fissure is here referred to as the "hidden" blade, whereas the blade closer to the lateral ventricle is called the "exposed" blade. Ammon's horn was subdivided into subfields CA1 and CA2/3.

The fascia dentata was further divided into three strata along the radial axis: namely, stratum (st.) moleculare, st. granulosum, and st. polymorphe. Within each CA subfield, four distinct strata were identified: st. oriens, st. pyramidale, st. radiatum, and st. lacunosummoleculare. The boundary for st. lucidum could not be reliably delineated, hence no measurement was made in this stratum. Moreover, no attempt was made to quantify NADPH-d-reactive cells in the pyramidal cell layer of the subiculum because of the high degree of overlap of positively stained somata of pyramidal neurons.

In addition, NADPH-d-reactive neuronal density scores were collected from the caudate-putamen at the level of dorsal hippocampus (corresponding to plate 96 of Paxinos and Watson, 1986). Because NADPHd-reactive neurons in the striatum are relatively evenly distributed, without a dorsoventral or a rostrocaudal gradient (Vincent et al., 1983), this should provide a representative measure of the density of NADPHd-reactive neurons in the neostriatum.

\section{Statistical analysis}

A two-way split-plot ANOVA was performed to examine any possible between-groups difference in the areal estimates of hippocampus at three different septotemporal levels.

Three separate ANOVAs were performed to analyze the density scores (numbers of NADPH-d-positive neurons per $\mathrm{mm}^{2}$ ) obtained in the hippocampus in each experiment. Before parametric analysis, all density scores were logarithmically transformed, using the function $\mathrm{f}(x)$ $=\log _{10}(x+10)$, to normalize the data distribution. All analyses were performed using the statistical package GENSTAT-5 (Release 3.1) implemented on a VAX mainframe computer. Post hoc $t$ tests were performed to assess the pattern of significant main effects and interaction terms, using the appropriate SE of the difference (SEd) of the means derived from the residual sum of square terms and degrees of freedom associated with the main effects or interaction of interest. The values of SEd were automatically calculated by the statistical program.

The first ANOVA was designed to assess any possible group difference in the density and distribution of NADPH-d reactivity in the fascia dentata. For this, a four-way split-plot ANOVA with three withinsubjects factors [septotemporal levels (dorsal, flexure, and ventral), subfields (exposed and hidden blades), and strata (st. moleculare, st. granulosum, and st. polymorphe)] and one between-subjects factor was used. The between-subjects factor was handling in Experiment 1 and stress in Experiment 2.

Another four-way split-plot ANOVA with the same between-subjects factor and within-subjects factors [septotemporal levels, subfields (CA2/3 and CA1), and strata (st. oriens, st. pyramidale, st. radiatum, and st. lacunosum-moleculare)] was used to analyze the density scores obtained in Ammon's horn.

The third ANOVA was designed to compare the fascia dentata and Ammon's horn and included density scores obtained from both hippocampal components. This was achieved by using a three-way split-plot 


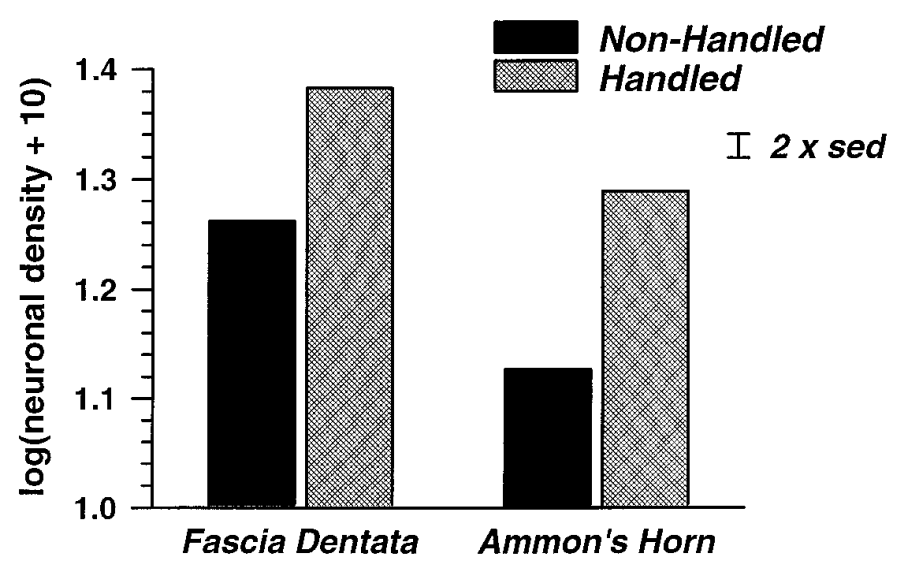

Figure 1. Mean log-transformed density scores in the fascia dentata and Ammon's horn in rats raised in the absence of neonatal handling (solid bars) and in rats that received regular neonatal handling (hatched bars). A log-transformed density score of unity corresponds to an untransformed score of zero. Error bar refers to the SE of difference (sed) of means derived from the error term associated with the interaction term between handling and hippocampus in the relevant ANOVA table (see Results).

ANOVA with the same between-subjects factor as the other two analyses and two within-subjects factors: septotemporal levels and hippocampus (fascia dentata and Ammon's horn). Because the fascia dentata and Ammon's horn are two anatomically distinct components of the hippocampus, the subdivision and the stratification of Ammon's horn and of the fascia dentata do not correspond; hence the factors strata and subfields were omitted in this analysis.

Finally, the density scores obtained from the neostriatum were analyzed using an independent Student's $t$ test for between-groups difference. No logarithmic transformation was needed in this analysis because the distribution of the raw data did not deviate from normality.

\section{RESULTS}

\section{Experiment 1. Neonatal nonhandling}

$N A D P H-d$ reactivity in the fascia dentata

There was a highly significant reduction in the density of NADPH-d reactive neurons in the fascia dentata $\left[F_{(1,4)}=89.48\right.$; $p<0.001]$ of the nonhandled group compared with the handled group (Figs. 1, 2). Representative micrographs showing the fascia dentata taken from a handled and nonhandled subject are illustrated in Figure 2, $G$ and $H$, respectively. Examination of the means of untransformed density scores indicated that the percentage reduction in the fascia dentata was $41.22 \%$. This effect was apparent across all three septotemporal levels examined, and the reduction in the hidden and exposed blades of fascia dentata was also comparable (Table 1A).

As shown in Table 1A, there was little variation in the density scores across different septotemporal levels $\left[F_{(2,8)}=2.26\right.$; NS $]$. It also seemed that the hidden blade had a higher density of NADPH-d-reactive neurons than the exposed blade; this trend was very close to statistical significance $\left[F_{(1,4)}=7.38 ; p=0.053\right]$ and was largely preserved in the nonhandled animals.

There was a clear gradient along the radial axis $\left[F_{(2,8)}=38.20\right.$; $p<0.001$ ], with the density of NADPH-d-positive neurons increasing significantly from the outer to inner stratum [minimum pairwise comparison: $\left.t_{(8)}=3.28 ; p<0.01\right]$. This gradient seemed to be less pronounced in the nonhandled group, yielding a nearsignificant interaction between handling and strata $\left[F_{(2,8)}=3.53\right.$; $p=0.080]$. Post hoc $t$ tests further revealed that there was no difference between st. granulosum and st. polymorphe in the nonhandled animals $(t<1.0$; NS) (Table 1A).

\section{NADPH-d reactivity in Ammon's horn}

The nonhandled group also showed a lower density of NADPHd-reactive neurons in Ammon's horn compared with the handled group (Figs. 1, 2). This was confirmed by a highly significant effect of handling $\left[F_{(1,4)}=312.63 ; p<0.001\right]$. Examination based on the untransformed mean density scores indicated a very substantial reduction of $64.28 \%$. Representative micrographs of Ammon's horn in Figure $2 C-F$ illustrate the difference in NADPH-d reactivity between a handled and a nonhandled rat.

As detailed in Table 1B, the magnitude of this reduction varied along the septotemporal and radial axes but was comparable between CA1 and CA2/3 subfield. The dorsal region was the most affected level among the three examined. Indeed, in the nonhandled group, the level of NADPH-d-reactive neuronal density at the dorsal level was significantly below those found in the flexure and ventral levels [minimum $t_{(12)}=3.74 ; p<0.01$ ] of the same group. On the other hand, the reduction along the radial axis was least pronounced in st. oriens. These impressions were confirmed by the significant interaction between handling and septotemporal levels $\left[F_{(2,8)}=5.96 ; p<0.05\right]$ and the significant interaction between handling and strata $\left[F_{(3,12)}=3.91 ; p<0.05\right]$.

Our results also showed that there was a clear difference in neuronal density of NADPH-d-reactive neurons between subfields CA1 and CA2/3 $\left[F_{(1,4)}=95.52 ; p<0.001\right]$, as well as among strata $\left[F_{(3,12)}=32.68 ; p<0.001\right]$. Further examination revealed that the pattern of variation among strata was itself different between subfields CA1 and CA2/3. Although there was a clear gradient of increasing density from the inner to outer layers in CA2/3, the density of NADPH-d-reactive neurons along the radial axis of CA1 initially rose from st. oriens to st. pyramidale but then fell and reached its lowest level in st. lacunosum-moleculare. This gave rise to the interaction between subfields and strata $\left[F_{(3,12)}=114.41 ; p<0.001\right]$. This characteristic difference between CA1 and CA2/3 was clearly retained in the nonhandled group, despite the presence of a significant handling $\times$ subfields $\times$ strata interaction $\left[F_{(3,12)}=9.03 ; p<0.001\right]$, which was simply attributable to the fact that the effect of nonhandling in subfield $\mathrm{CA} 2 / 3$ was most pronounced in st. lacunosummoleculare, whereas in CA1 it was most pronounced in st. pyramidale, and these two particular strata were the cell layers showing the highest density of NADPH-d-reactive neurons in CA2/3 and CA1, respectively, in the handled group.

\section{Comparison between fascia dentata and Ammon's horn}

This analysis incorporated the density scores from both the fascia dentata and Ammon's horn and thus allowed direct comparison between these two hippocampal components. It yielded a significant effect of handling $\left[F_{(1,4)}=190.14 ; p<0.001\right]$, confirming the results outlined above. Furthermore, it indicated that the fascia dentata as a whole showed a higher density of NADPH-d neuronal reactivity than Ammon's horn $\left[F_{(1,4)}=1568.66 ; p<0.001\right]$.

More importantly, the analysis revealed a significant interaction between handling and hippocampus $\left[F_{(1,4)}=52.97 ; p<\right.$ 0.001], because Ammon's horn was more vulnerable to the effect of nonhandling than was the fascia dentata (Fig. 1).

\section{Gross histology and hippocampal areal comparison}

Inspection of the Nissl stain materials gave no indication of any gross histological differences between handled and nonhandled group (Fig. 3). Attempts to estimate the neuronal density in cresyl violet stained sections proved to be difficult and would not yield 

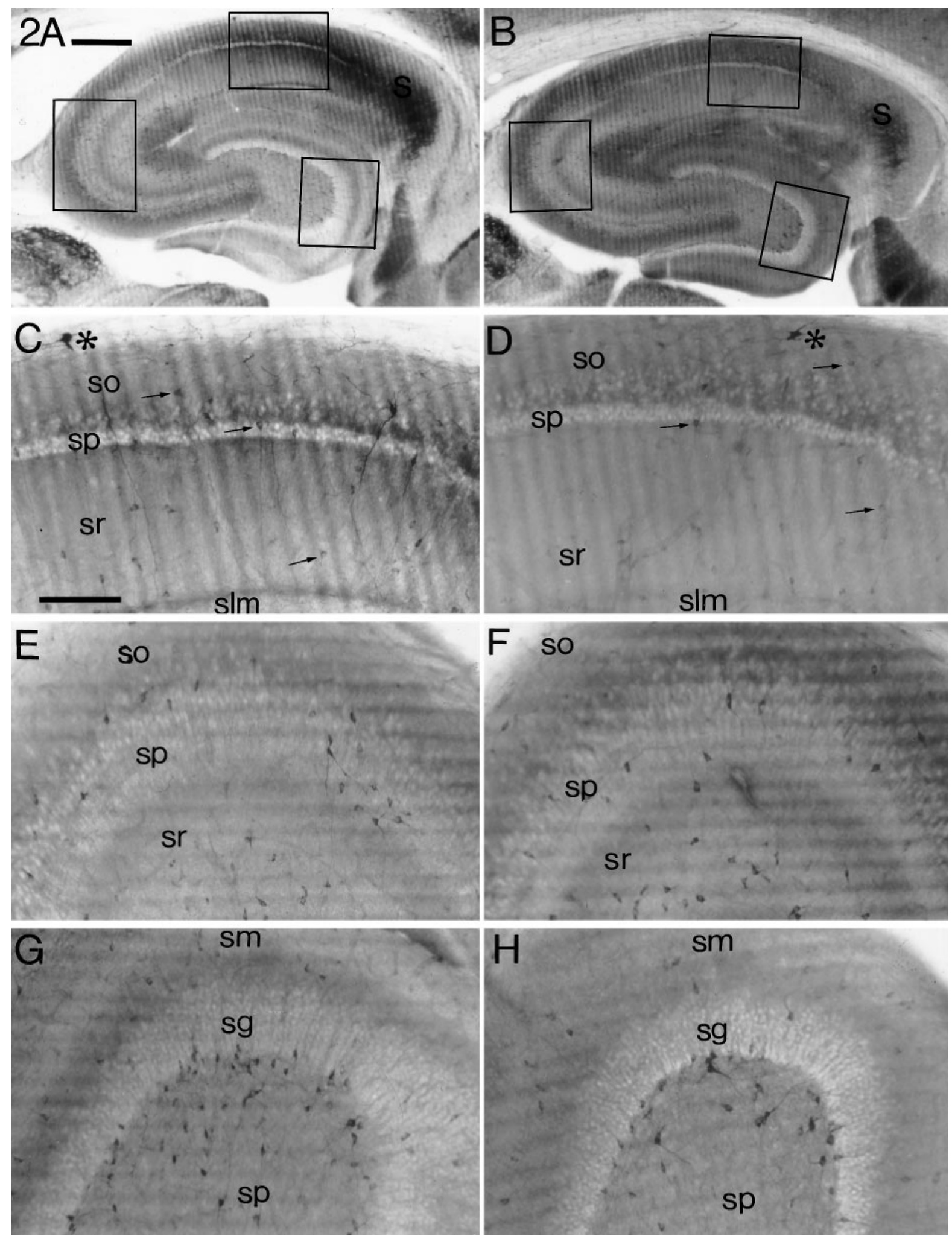

Figure 2. Histochemistry for NADPH-d in sections of hippocampus from the brains of handled $(A, C, E, G)$ and nonhandled $(B, D, F, H)$ rats. $A, B$, Low-power photomicrographs of similar levels in the hippocampus where it can clearly be seen that the principal cells are generally NADPH-d-negative, except for neurons in the subiculum $(s)$. The number of NADPH-d-reactive neurons is not related to the apparent darkness of staining (compare $A$ and $B, C$ and $D$ ), which reflects only the longer incubation time for $B$. The exact shape of the structures is dependent on the precise plane of section. The upper boxed areas (CA1) appear in $C$ and $D$, the boxed areas to the right in $E$ and $F(\mathrm{CA} 2 / 3)$, and the boxed areas to the left (dentate gyrus) in $G$ and $H$, respectively. In $C-F$, the layers st. oriens $(s o)$, st. pyramidale $(s p)$, and st. radiatum $(s r)$ are indicated, as is the st. lacunosum-moleculare $(s l m)$ in $C$ and $D$. In $G$ and $H$, the layers of the dentate gyrus, the st. moleculare $(s m)$, st. granulosum $(s g)$, and st. polymorphe $(s p)$ are indicated. In the CA1 region $(C, D)$ it is possible to identify two types of NADPH-d-reactive neurons: a large, densely stained type (asterisks) often associated with the alvear fibers, and a less densely stained type (arrows) found in all layers. Scale bars: $A, B, 500 \mu \mathrm{m} ; C-H, 200 \mu \mathrm{m}$. 
Table 1. Effects of neonatal handling/nonhandling on the density of NADPH-d-reactive neurons in the fascia dentata (A) and Ammon's horn (B)

\begin{tabular}{|c|c|c|c|}
\hline & Handled & Nonhandled & SEd \\
\hline \multicolumn{4}{|l|}{ A. Dentate gyrus } \\
\hline Septotemporal axis & & & 0.0206 \\
\hline Dorsal & $1.389(15.87)$ & $1.247(8.13)$ & \\
\hline Flexure & $1.386(15.47)$ & $1.291(10.88)$ & \\
\hline Ventral & $1.372(14.67)$ & $1.247(8.02)$ & \\
\hline Transverse axis & & & 0.0244 \\
\hline "Hidden" blade & $1.425(17.84)$ & $1.276(9.55)$ & \\
\hline "Exposed" blade & $1.340(12.83)$ & $1.248(8.47)$ & \\
\hline Radial axis & & & 0.0305 \\
\hline St. moleculare & $1.252(8.00)$ & $1.168(4.82)$ & \\
\hline St. granulosum & $1.381(14.60)$ & $1.296(10.88)$ & \\
\hline St. polymorphe & $1.515(23.40)$ & $1.320(11.32)$ & \\
\hline \multicolumn{4}{|l|}{ B. Ammon's horn } \\
\hline Septotemporal axis & & & 0.0213 \\
\hline Dorsal & $1.295(11.14)$ & $1.067(1.79)$ & \\
\hline Flexure & $1.277(10.13)$ & $1.158(2.97)$ & \\
\hline Ventral & $1.297(10.64)$ & $1.155(4.62)$ & \\
\hline Transverse axis & & & 0.0126 \\
\hline $\mathrm{CA} 2 / 3$ & 1.337 (13.07) & $1.163(4.97)$ & \\
\hline CA1 & $1.242(8.21)$ & $1.090(2.62)$ & \\
\hline Radial axis & & & 0.0203 \\
\hline St. oriens & $1.173(5.03)$ & $1.068(1.75)$ & \\
\hline St. pyramidale & $1.355(13.19)$ & $1.155(4.65)$ & \\
\hline St. radiatum & $1.305(10.42)$ & $1.141(4.07)$ & \\
\hline St. lacunosum-moleculare & $1.325(13.90)$ & $1.142(4.69)$ & \\
\hline
\end{tabular}

Means log-transformed and untransformed (in parentheses) density scores at three septotemporal levels, or in different hippocampal subfields (fascia dentata, CA2/3, and CA1), or among different cell layers (strata) are illustrated. SEd refers to the SE of the difference of the log-transformed means for between-groups comparison in the corresponding hippocampal axis.

reliable estimates because the sections were too thick $(70 \mu \mathrm{m})$ for this purpose.

The comparison of hippocampal areal estimates (obtained in NADPH-d-stained materials) also yielded no significant betweengroups difference and no significant interaction between handling and septotemporal levels; however, we cannot exclude the possible existence of subtle ultrastructural differences that might be detectable at the electron microscope level.

\section{NADPH-d neuronal reactivity in the neostriatum}

There was no significant difference in the density of NADPH-dpositive striatal neurons between groups $(t<1.0)$. Although no measurement was made with respect to cell type and intensity of NADPH-d staining, visual inspection suggested that these also did not differ between groups.

\section{Experiment 2. Prenatal stress}

One brain from the unstressed control group was excluded from histomorphometric analysis because of poor perfusion and/or fixation. The brain sections of this animal partially disintegrated during histochemical processing and therefore were unsuitable for histomorphometric evaluation.

\section{$N A D P H-d$ reactivity in the fascia dentata}

The distribution of NADPH-d-reactive neurons in the fascia dentata resembled that observed in Experiment 1 (Figs. 4, 5). Representative micrographs showing the fascia dentata taken from an unstressed control rat and from a prenatally stressed rat are illustrated in Figure 5, $G$ and $H$, respectively.

Statistical analysis confirmed that prenatal stress significantly reduced the density of NADPH-d-reactive neurons in the fascia dentata $\left[F_{(1,5)}=28.35 ; p<0.005\right]$. Calculation based on the means of untransformed density scores showed an average percentage reduction of $35.38 \%$. This effect was observed in all three septotemporal levels. Although this effect appeared less pronounced in the dorsal region (Table 2A), the interaction between stress and septotemporal levels did not attain statistical significance $\left[F_{(2,10)}=1.80 ; \mathrm{NS}\right]$. In this experiment, but not in Experiment 1 , the neuronal density of NADPH-d neurons exhibited significant variation along the septotemporal axis $\left[F_{(2,10)}=7.07\right.$; $p<0.05]$. Post hoc $t$ comparisons indicated that the flexure region showed the highest density [minimum $t_{(10)}=3.1813 ; p<0.01$ ], whereas the dorsal and ventral regions did not differ from each other $(t<1.0)$. This trend along the septotemporal axis was preserved in the prenatal stress group.

As in Experiment 1, there was no significant difference between the hidden blade and the exposed blade of fascia dentata $\left[F_{(1,5)}=4.85 ; \mathrm{NS}\right]$. The effect of prenatal stress was comparable between the two blades (Table $2 \mathrm{~A}$ ).

The gradient along the radial axis $\left[F_{(2,10)}=205.12 ; p<0.001\right]$ was also identical to that reported in Experiment 1, with the density of NADPH-d-positive neurons increasing significantly from the outer to inner stratum [minimum pairwise comparison: $\left.t_{(10)}=7.625 ; p<0.01\right]$. As illustrated in Table 2A, the effect of prenatal stress clearly varied along the radial axis, yielding a highly significant interaction between stress and strata $\left[F_{(2,10)}=\right.$ 10.57; $p<0.005]$. Post hoc $t$ comparisons indicated that when compared with the control group, prenatal stress significantly reduced NADPH-d neuronal density in st. moleculare and st. polymorphe $\left[t_{(10)}=2.54 ; p<0.05\right.$; and $\left.t_{(10)}=6.87 ; p<0.01\right]$, but not in st. granulosum $\left[t_{(10)}=1.11\right.$; NS].

\section{NADPH-d reactivity in Ammon's horn}

Prenatal stress also reduced the density of NADPH-d-reactive neurons in Ammon's horn (Fig. 4, Table 2B). Examination of the means of untransformed density scores indicated that the average percentage reduction in Ammon's horn was 41.73\%. Despite the high degree of reduction, this effect was statistically less robust than that observed in the fascia dentata (see above). The effect was very close to, but did not attain, statistical significance $\left[F_{(1,5)}\right.$ $=5.95 ; p=0.059]$.

As in the fascia dentata, it appeared that the dorsal region was selectively less affected by prenatal stress (Table 2B), but the interaction between stress and septotemporal levels failed to attain statistical significance $\left[F_{(2,10)}=1.05 ; \mathrm{NS}\right]$. On the other hand, the reduction in subfields CA1 and CA2/3 was comparable, and the reduction also appeared to be uniform across different strata (Table 2B). In agreement with these impressions, stress did not interact significantly with either subfields or strata.

Overall, prenatal stress caused a general reduction of NADPHd-reactive neuronal density in Ammon's horn, whereas it conserved the characteristic regional variations that were also present in Ammon's horn of control animals.

The regional distribution of NADPH-d-positive neurons within Ammon's horn in this experiment was similar to that seen in Experiment 1. The neuronal density of NADPH-d-reactive neurons showed clear variation along the septotemporal axis $\left[F_{(2,10)}=6.03 ; p<0.05\right]$, between subfields $\left[F_{(1,5)}=33.19 ; p<\right.$ $0.005]$, and along the radial axis $\left[F_{(3,15)}=24.07 ; p<0.001\right]$. These 

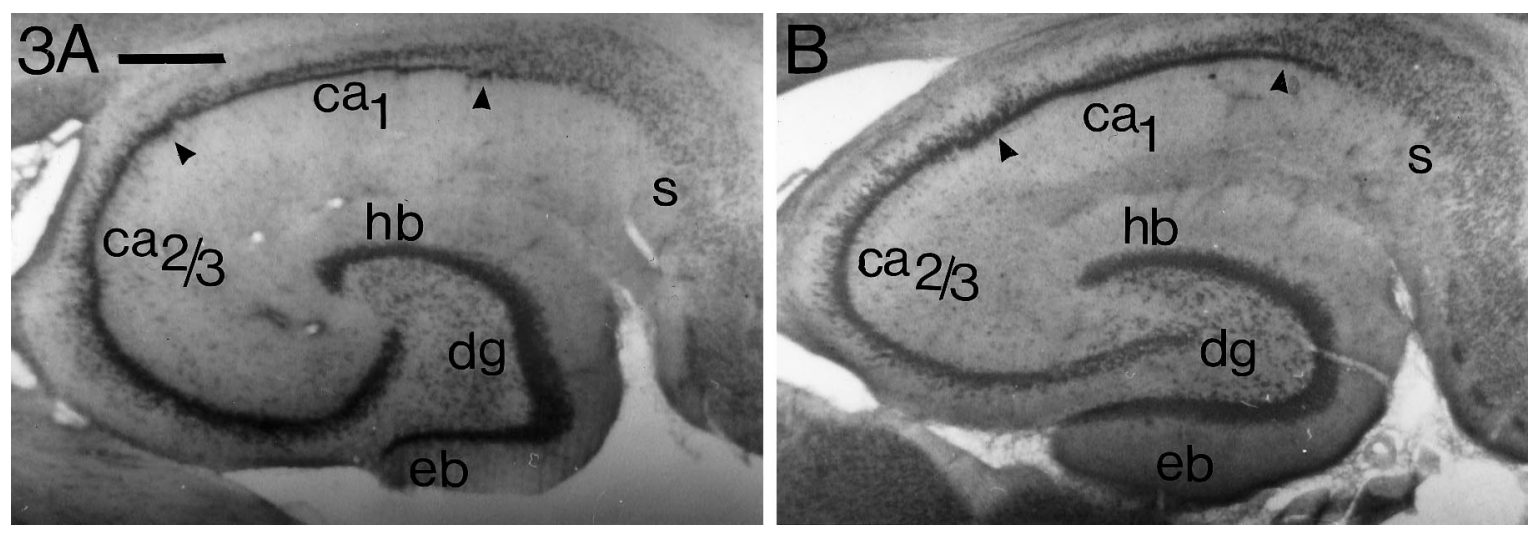

Figure 3. Nissl-stained sections of the hippocampus from handled $(A)$ and nonhandled $(B)$ rats. The approximate boundaries between the subfields $\left(c a_{1}\right.$, $c a_{2 / 3}$ ) of Ammon's horn are indicated by arrowheads, and the subiculum $(s)$ is recognized by the looser distribution of the principal neurons. In the dentate gyrus $(d g)$, the hidden $(h b)$ and exposed $(e b)$ blades are indicated. The exact shape of the structures is dependent on the precise plane of section, but there are no clear differences between the two hippocampi. Scale bar (shown in $A$ ): $500 \mu \mathrm{m}$.

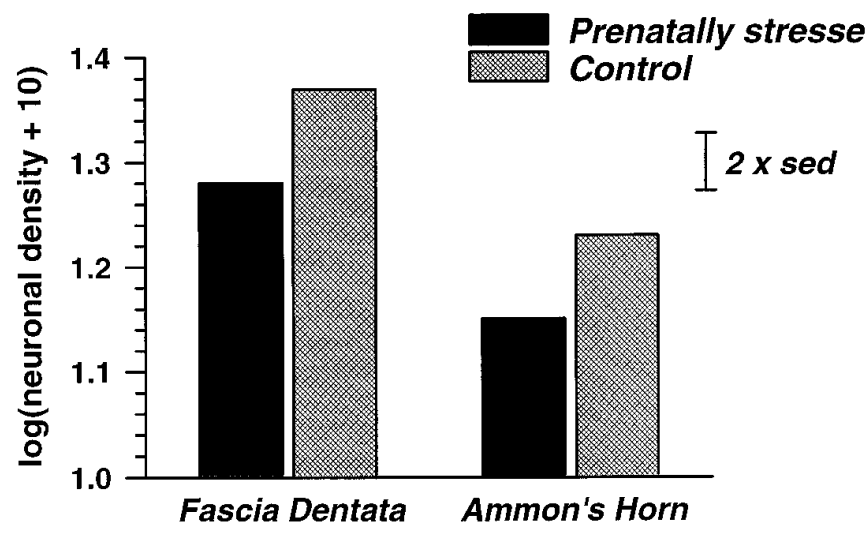

Figure 4. Mean log-transformed density scores in the fascia dentata and Ammon's horn in prenatally stressed rats (solid bars) and unstressed control rats (hatched bars). A log-transformed density score of unity corresponds to an untransformed score of zero. Error bar refers to the SE of difference (sed) of means derived from the error term associated with the interaction term between handling and hippocampus in the relevant ANOVA table (see Results).

variations closely approximated those seen in Experiment 1. Furthermore, the interaction between subfields and strata also attained statistical significance here $\left[F_{(3,15)}=30.51 ; p<0.001\right]$ and in a form that replicated the pattern seen in Experiment 1.

What sets the present experiment apart from Experiment 1 was the presence of a significant interaction between septotemporal levels and strata $\left[F_{(6,30)}=2.97 ; p<0.05\right]$ here. This was because although st. pyramidale was the cell layer that showed the highest density of NADPH-d-reactive neurons in the ventral and flexure regions, this was not the case in the dorsal region.

\section{Comparison between fascia dentata and Ammon's horn}

In the analysis that combined the density scores from both the fascia dentata and Ammon's horn, the effect of prenatal stress was again highly significant $\left[F_{(1,5)}=13.13 ; p<0.05\right]$, confirming the results outlined above. Second, the interaction between stress and hippocampus did not attain significance $(F<1.0)$. This indicated that prenatal stress reduced NADPH-d-reactive neuronal density in both fascia dentata and Ammon's horn to a similar extent (Fig. 1 ), even though the individual analyses had yielded a highly significant effect of prenatal stress in the fascia dentata $(p<0.01)$ and only a marginal effect in Ammon's horn $(p=0.059)$.

\section{Gross histology and hippocampal areal comparison}

Light microscopic examination of the Nissl-stained materials gave no indication of any gross histological differences between controls and prenatally stressed rats. No attempts were made to measure neuronal density in cresyl violet sections because of section thickness.

Again, there was no indication of any significant difference in hippocampal areal estimates (obtained in NADPH-d-stained materials) between groups, or of a significant interaction between prenatal stress and septotemporal levels.

These results paralleled those of Experiment 1 in which there was also no evidence for any gross histological difference, or volumetric change, between groups in the hippocampus, but we cannot exclude the possibility of subtle ultrastructural changes.

\section{$N A D P H-d$ reactivity in the neostriatum}

There was no significant difference in the density of NADPH-dpositive neurons in the neostriatum between prenatally stressed rats and control rats born to unstressed dams $(t<1.0)$.

\section{DISCUSSION}

As described previously (Valtschanoff et al., 1993), NADPH-dreactive neurons in the hippocampal formation are generally considered to be local circuit neurons. Three types of neurons can be discriminated on morphological grounds, of which the first two are found in all regions of Ammon's horn and the fascia dentata. The first are large, densely labeled multipolar neurons with long, coarse, smooth, or sometimes varicose dendrites. These neurons are often found in association with fiber tracts. The second type of neuron has a smaller cell body that often gives rise to bipolar dendrites, which can also be very long but are finer and almost always varicose. The third type of neuron is found almost exclusively in the subiculum [although it has also been reported to be present in CA1-3 (Vaid et al., 1996)], and on the basis of their location and shape, these actually may be a subpopulation of principal pyramidal neurons of this region. This study did not discriminate between the first two types and did not evaluate the third type because of the high degree of overlap in the subiculum, which made counting difficult.

The present study provides the first quantitative analysis on the topographical variation of the density of NADPH-d-reactive neurons in the hippocampus. In particular, our results indicate that the fascia dentata and CA1 and CA2/3 hippocampal subfields 

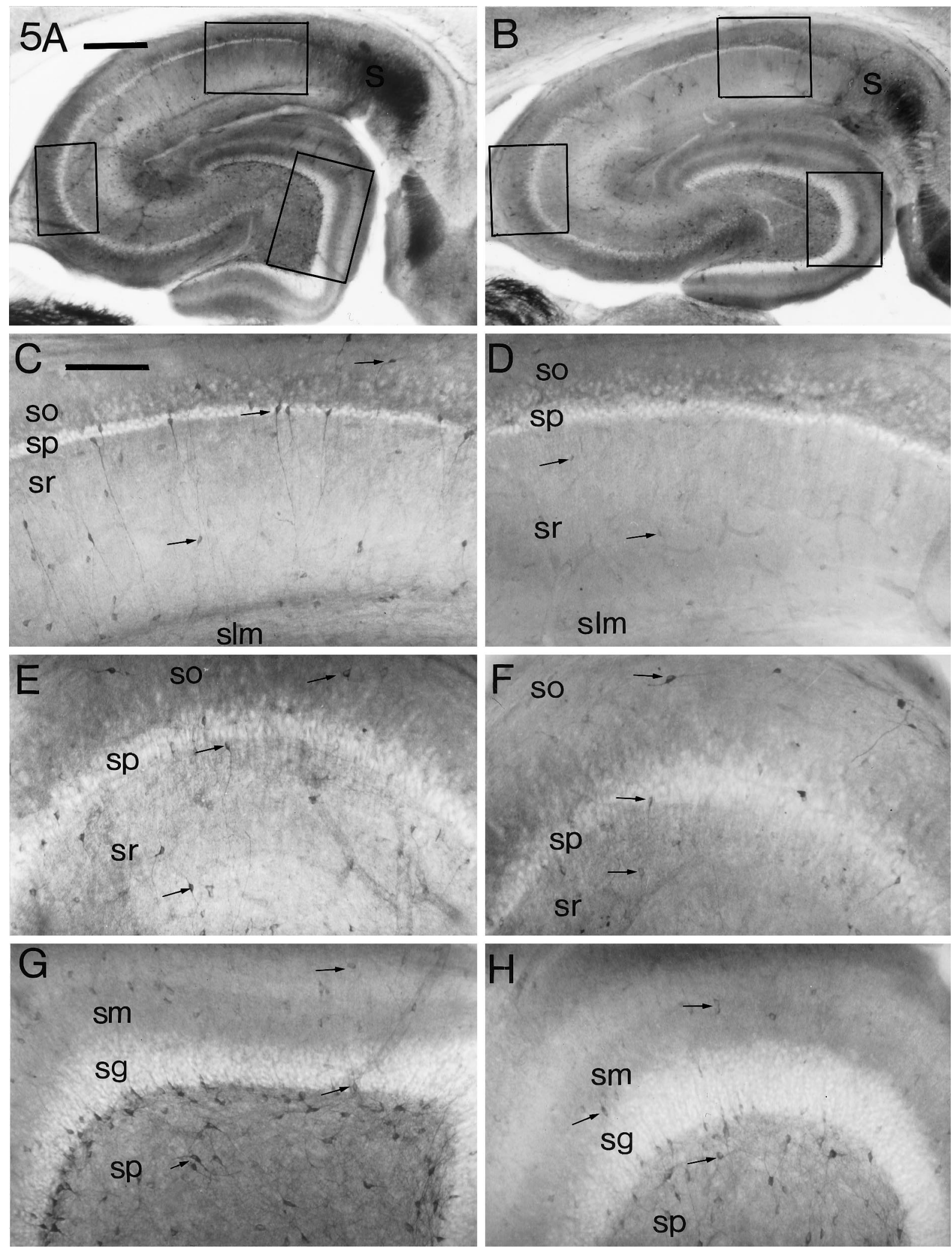

Figure 5. Histochemistry for NADPH-d in sections of hippocampus from the brains of control $(A, C, E, G)$ and prenatally stressed $(B, D, F, H)$ rats. $A, B$, Low-power photomicrographs of similar levels in the hippocampus where it can clearly be seen that the principal cells are NADPH-d-negative, except in the subiculum (s). The exact shape of the structures is dependent on the precise plane of section. The upper boxed areas (CA1) appear in $C$ and $D$, the boxed areas to the right in $E$ and $F(\mathrm{CA} 2 / 3)$, and the boxed areas to the left (dentate gyrus) in $G$ and $H$, respectively. In $C-F$, the layers st. oriens (so), st. pyramidale ( $s p)$, and st. radiatum $(s r)$ are indicated, as is the st. lacunosum-moleculare ( $\operatorname{sim}$ ) in $C$ and $D$. In $G$ and $H$, the layers of the dentate gyrus, the st. moleculare $(s m)$, st. granulosum $(s g)$, and the st. polymorphe $(s p)$ are indicated. In $C-H$, some NADPH-d-positive neurons are indicated with arrows. Scale bars: $A, B, 500 \mu \mathrm{m} ; C-H, 200 \mu \mathrm{m}$. 


\begin{tabular}{|c|c|c|c|}
\hline & Control & Stress & SEd \\
\hline \multicolumn{4}{|l|}{ A. Dentate gyrus } \\
\hline Septotemporal axis & & & 0.0330 \\
\hline Dorsal & $1.317(15.39)$ & $1.277(9.61)$ & \\
\hline Flexure & $1.426(19.17)$ & $1.330(12.68)$ & \\
\hline Ventral & $1.366(12.40)$ & $1.233(8.08)$ & \\
\hline Transverse axis & & & 0.0210 \\
\hline "Hidden" blade & $1.391(17.00)$ & $1.287(10.58)$ & \\
\hline "Exposed" blade & $1.349(14.31)$ & $1.273(9.67)$ & \\
\hline Radial axis & & & 0.0255 \\
\hline St. moleculare & $1.177(5.20)$ & $1.113(3.16)$ & \\
\hline St. granulosum & $1.361(13.65)$ & $1.333(11.92)$ & \\
\hline St. polymorphe & $1.570(28.12)$ & $1.395(15.29)$ & \\
\hline \multicolumn{4}{|l|}{ B. Ammon's horn } \\
\hline Septotemporal axis & & & 0.0423 \\
\hline Dorsal & $1.167(8.82)$ & $1.120(5.19)$ & \\
\hline Flexure & $1.281(10.61)$ & $1.167(5.68)$ & \\
\hline Ventral & $1.244(5.58)$ & $1.164(3.73)$ & \\
\hline Transverse axis & & & 0.0404 \\
\hline $\mathrm{CA} 2 / 3$ & $1.304(10.07)$ & $1.213(6.66)$ & \\
\hline CA1 & $1.157(5.61)$ & $1.088(3.07)$ & \\
\hline Radial axis & & & 0.0395 \\
\hline St. oriens & $1.137(3.95)$ & $1.070(1.81)$ & \\
\hline St. pyramidale & $1.281(10.82)$ & $1.218(7.61)$ & \\
\hline St. radiatum & $1.249(8.48)$ & $1.163(4.96)$ & \\
\hline St. lacunosum-moleculare & $1.255(10.11)$ & $1.152(5.07)$ & \\
\hline
\end{tabular}

Means log-transformed and untransformed (in parentheses) density scores at three septotemporal levels, or in different hippocampal subfields (fascia dentata, CA2/3, and CA1), or among different cell layers (strata) are illustrated. SEd refers to the SE of the difference of the log-transformed means for between-groups comparison in the corresponding hippocampal axis.

each show a distinct gradient of NADPH-d expression along their respective radial axes. The present study also goes on to show unequivocally that both neonatal nonhandling and prenatal stress reduce the density of NADPH-d-reactive neurons in the hippocampus. In both experiments, although this reduction was in all components of the hippocampus, the magnitude of this effect exhibited significant variations along different hippocampal axes, as indicated by the presence of significant higher-order interactions (see Results). Furthermore, the lack of between-groups difference in the density of NADPH-d-positive neurons in the neostriatum indicates that the early manipulations used here did not indiscriminately reduce NADPH-d reactivity throughout all brain regions. It would be very interesting to assess the possibility that other extra-hippocampal regions, such as the amygdala, the septum, and the neocortical areas may be similarly affected by these early behavioral/environmental manipulations.

In addition, we carried out areal comparisons of the hippocampus at the three septotemporal levels examined here, to assess possible volumetric change of the hippocampus that might undermine our conclusion. The results demonstrated that there were no between-groups difference in the volume of the fascia dentata and Ammon's horn in both experiments. Under this condition, the counting method used here was appropriate. Indeed the only possible volumetric change that could account for our results would be an increase in the volume of hippocampus in the prenatally stressed group and the nonhandling group, relative to their respective comparison group. If such a change were present, it would have been easily detectable, yet we have no evidence for any change in hippocampal volume. Alternatively, our observation might be confounded by an absolute change of neuronal density as such (even in the absence of volumetric change). Although we did not have estimates of hippocampal neuronal density because of section thickness in the cresyl violet materials, there is an independent report to suggest that there was no difference in hippocampal neuronal density in handled versus nonhandled rats at 6 months of age (Meaney et al., 1988). We cannot exclude the possibility, however, that such a difference may exist in Experiment 2 with prenatal stress.

In the absence of volumetric change or an alternation of absolute hippocampal neuronal density, our finding would imply that there was a reduction in the absolute number of neurons expressing NADPH-d activity in the fascia dentata and Ammon's horn in prenatally stressed and neonatally nonhandled rats. A reduction in the density and/or number of NADPH-d-reactive neurons, however, can be attributed to either a loss of such neurons or an absence of NADPH-d activity in neurons that normally express it. Although our present data cannot decide between these two alternatives, the absence of volumetric change and the lack of gross histological alteration, as suggested by the Nissl-stained materials, may favor the latter alternative. This suggestion is consistent with the hypothesis that these early behavioral manipulations interfere with the development of such neurons into NO-producing neurons (i.e., neurogenesis) rather than prune preexisting NO-producing neurons subsequent to their development (i.e., selective neurodegeneration).

The similarity between the results obtained in the two experiments reported here is consistent with the suggestion that the mechanism whereby prenatal stress and neonatal nonhandling affect the neurodevelopment of the hippocampal NO system may involve a common cascade of events. As mentioned in the introductory remarks, one such common factor may be hypersecretion of GC in response to stress later in adulthood in these animals (Levine, 1957, 1962; Ader and Grota, 1969; Hess et al., 1969; Fride et al., 1986). If our present observations were indeed causally related to an elevation of plasma GC, which in the present study would be induced by mild environmental stress experience in normal laboratory conditions as opposed to explicit experimental stress, it would imply that the effects on the hippocampus seen here might be prevented by interventions designed to suppress plasma GC levels, e.g., radical adrenalectomy or GC antagonists treatment. Our present results also highlight the interesting possibility that the effect of prenatal stress on the hippocampal NO system may be "corrected" by regular administration of neonatal handling.

Given that the hippocampal NO system can be significantly compromised by prenatal stress and neonatal nonhandling, to what extent could the behavioral abnormalities seen in these animals be attributed to hippocampal NO dysfunction? NO is a candidate retrograde messenger involved in the induction of some forms of hippocampal long-term potentiation (LTP) and longterm depression (LTD) (for review, see Bear and Malenka, 1994; Medina and Izquierdo, 1996). Hence it is likely that some of the learning impairment seen in prenatally stressed and neonatally nonhandled rats might be attributed to a reduction of hippocampal NO production, although pharmacological manipulations in normal animals using NO inhibitors have so far yielded mixed results as to whether a reduction of NO production can indeed prevent the formation of LTP or produce any significant memory 
impairment (Chapman et al., 1992; Bannerman et al., 1994a,b,c; Fin et al., 1995; Good, 1996).

We have demonstrated previously that neonatal nonhandling can lead to an attenuation of latent inhibition (Weiner et al., 1985, 1987; Feldon and Weiner, 1988, 1992; Feldon et al., 1990). Recently, there is also evidence to suggest that prenatal stress can similarly disrupt the normal development of latent inhibition (J. Feldon and I. Weiner, unpublished observation). Because similar attenuation is also seen after direct hippocampal system damage (Kaye and Pearce, 1987a,b; Hans et al., 1995; Yee et al., 1995), it seems plausible that prenatal stress and neonatal nonhandling might attenuate latent inhibition through their deleterious effects on the hippocampal NO system. Loss of latent inhibition has been proposed to be a marker for the attentional deficits associated with positive symptoms in human psychosis (Gray et al., 1991, 1995). Temporal lobe (including the hippocampus and parahippocampal region) neuropathology has been the most consistent anatomical finding in the brains of schizophrenics (e.g., Scheibel and Kovelman, 1981; Kovelman and Scheibel, 1986; Altshulter et al., 1987; Roberts, 1991; Roberts and Horton, 1992), and it has been suggested that such an abnormality may be developmental in nature (Weinberger, 1987; Jaskiw and Weinberger, 1992; Lipska et al., 1993). In particular, significant alteration in the distribution of NADPH-d-reactive neurons has been reported in the temporal lobes of schizophrenic patients (Akbarian et al., 1993). Our present results thus lend support to the suggestion that early manipulations such as prenatal stress or neonatal nonhandling may provide a neurodevelopmental model of schizophrenia (Feldon and Weiner, 1992). This is particularly interesting when one considers that NO may play a critical role in synaptogenesis (Ma et al., 1991; Hess et al., 1993; Kalb and Agostini, 1993; Ogilive et al., 1995), and thus a reduction of NO production in the hippocampus could itself have far reaching consequences in the normal development of the hippocampus and adjacent cortices.

\section{REFERENCES}

Ader R, Grota LJ (1969) Effects of early experience on adrenocortical reactivity. Physiol Behav 4:303-305.

Akbarian S, Viñuela A, Kim JJ, Potkin SG, Bunney WE, Jones E (1993) Distorted distribution of nicotinamide-adenine dinucleotide phosphatediaphorase neurons in temporal lobe of schizophrenics implies anomalous cortical development. Arch Gen Psychiatry 50:178-187.

Altman J, Das G (1965) Autoradiographic and histological evidence of postnatal hippocampal neurogenesis in rats. J Comp Neurol 124:319-336.

Alshulter LL, Conrad A, Kovelman JA, Scheibel A (1987) Hippocampal pyramidal cell orientation in schizophrenia. Arch Gen Psychiatry 44:1094-1098.

Angevine JB (1965) Time of neuron origin in the hippocampal region: an autoradiographic study in the mouse. Exp Neurol [Suppl] 13:1-70.

Archer JE, Blackman DE (1971) Prenatal psychological stress and offspring behavior in rats and mice. Dev Psychobiol 3:193-248.

Bannerman DM, Butcher SP, Morris RGM (1994a) intracerebroventricular injection of a nitric oxide synthase inhibitor does not affect longterm slope potentiation in vivo. Neuropharmacology 33:1387-1397.

Bannerman DM, Chapman PF, Kelly PAT, Butcher SP, Morris RGM (1994b) Inhibition of nitric oxide synthase does not impair spatial learning. J Neurosci 14:7404-7414.

Bannerman DM, Chapman PF, Kelly PAT, Butcher SP, Morris RGM (1994c) Inhibition of nitric oxide synthase does not prevent the induction of long-term potentiation in vivo. J Neurosci 14:7415-7425.

Bear MF, Malenka RC (1994) Synaptic plasticity: LTP and LTD. Curr Opin Neurobiol 4:389-399.

Benes FM, Turtle M, Khan Y, Farol P (1994) Myelination of a key zone in the hippocampal formation occurs in the human brain during childhood, adolescence, and adulthood. Arch Gen Psychiatry 51:477-484.

Bredt DS, Glatt CE, Hwang PM, Fotuhi M, Dawson TM, Snyder SH
(1991) Nitric oxide synthase protein and mRNA are discretely localized in neuronal populations of the mammalian CNS together with NADPH diaphorase. Neuron 7:615-624.

Brody BA, Kinney HC, Kloman AS, Gilles FH (1987) Sequence of central nervous system myelination in human infancy. I. An autopsy study of myelination. J Neuropathol Exp Neurol 46:283-301.

Chapman PF, Atkins CM, Allen MT (1992) Inhibition of nitric oxide synthesis impairs two different forms of learning. NeuroReport 3:567-570.

Dawson TM, Bredt DS, Fotuhi M, Hwang PM, Snyder SH (1991) Nitric oxide synthase and neuronal NADPH diaphorase are identical in brain and peripheral tissues. Proc Natl Acad Sci USA 88:7797-7801.

Deminère JM, Piazza PV, Guegan G, Abrous N, Maccari S, LeMoal M, Simon H (1992) Increased locomotor response to novelty and propensity for intravenous amphetamine self-administration in adult offspring of stressed mothers. Brain Res 586:135-139.

Dun NJ, Dun SL, Wong RKS, Föstermann U (1994) Colocalization of nitric oxide synthase and somatostatin immunoreactivity in rat dentate hilar neurons. Proc Natl Acad Sci USA 91:2955-2959.

Feldon J, Weiner I (1992) From an animal model of an attentional deficit towards new insights into the pathophysiology of schizophrenia. J Psychiatr Res 26:367-382.

Feldon J, Weiner I (1988) Long-term attentional deficit in nonhandled males: possible involvement of the dopaminergic system. Psychopharmacology 95:231-236.

Feldon J, Avnimelech-Gigus N, Weiner I (1990) The effects of pre- and post-weaning rearing conditions on latent inhibition and partial reinforcement extinction effect in male rats. Behav Neural Biol 53:189-204.

Fin C, Da Cunha C, Bromberg E, Schmitz PK, Bianchin M, Medina JH, Izquierdi I (1995) Experiments suggesting a role for nitric oxide in the hippocampus in memory. Neurobiol Learning Memory 63:113-115.

Fride E, Weinstock M (1988) Prenatal stress increases anxiety related behavior and alters cerebral lateralization of dopamine activity. Life Sci 42:1059-1065.

Fride E, Dan Y, Feldon J, Halevy G, Weinstock M (1986) Effects of prenatal stress on vulnerability to stress in prepubertal and adult rats. Physiol Behav 37:681-687.

Good M (1996) Targeted deletion of neuronal nitric oxide: a step closer to understanding its functional significance? Trends Neurosci 3:83-84.

Gray JA, Feldon J, Rawlins JNP, Hemsley DR, Smith AD (1991) The neuropsychology of schizophrenia. Behav Brain Sci 14:1-81.

Gray JA, Joseph MH, Hemsley DR, Young AMJ, Warburton EC, Boulenguez P, Grigoryan GA, Peters SL, Rawlins JNP, Tai CT, Yee BK, Cassaday HJ, Weiner I, Gal G, Gusak O, Joel D, Shadrach E, Shalev U, Tarrash R, Feldon J (1995) The role of mesolimbic dopaminergic and retrohippocampal afferents to the nucleus accumbens in latent inhibition: implications for schizophrenia. Behav Brain Res 71:19-31.

Greenberg G, Bursdal C (1982) Animal colony practices in North American academic institutions: a survey. J Gen Psychol 106:165-173.

Hans JS, Callagher M, Holland P (1995) Hippocampal lesions disrupt decrements but not increments in conditioned stimulus processing. J Neurosci 15:7323-7329.

Hess JL, Denenberg VH, Zarrow MX, Pfeifer WD (1969) Modification of the corticosterone response curve as a function of handling in infancy. Physiol Behav 4:109-112.

Hess DT, Patterson SI, Smith DS, Skene JH (1993) Neuronal growth cone collapse and inhibition of protein fatty acylation by nitric oxide. Nature 366:562-565.

Hope BT, Vincent SR (1989) Histochemical characterization of neuronal NADPH-diaphorase. J Histochem Cytochem 37:653-661.

Hope BT, Michael GJ, Knigge KM, Vincent SR (1991) Neuronal NADPH diaphorase is nitric oxide synthase. Proc Natl Acad Sci USA 88:2811-2814.

Jaskiw GE, Weinberger DR (1992) Dopamine and schizophrenia: a cortically corrective perspective. Semin Neurosci 4:179-188.

Kalb RG, Agostini J (1993) Molecular evidence for nitric oxidemediated motor neuron development. Neuroscience 57:1-8.

Kaye H, Pearce JM (1987a) Hippocampal lesions attenuate latent inhibition and the decline of the orienting response in rats. Q J Exp Psych [B] 39:107-125.

Kaye H, Pearce JM (1987b) Hippocampal lesions attenuate latent inhibition of CS and of a neutral stimulus. Psychobiology 15:293-299.

Kovelman JA, Scheibel AB (1986) A neurohistologic correlate of schizophrenia. Biol Psychiatry 19:1601-1621.

Kretschmann H-J, Kammradt G, Krauthausen I, Sauer B, Wingert F 
(1986) Growth of the hippocampal formation in man. Bibl Anat 28:27-52.

LaRocque S, O'Donnell D, Gianoulakis C, Seckl JR, Meaney MJ (1992) Postnatal handling in the rat alters hippocampal glucocorticoid receptor gene expression. Soc Neurosci Abstr 18:479.

Levine S (1957) Infantile experience and resistance to physiological stress. Science 126:405-406.

Levine S (1960) Stimulation in infancy. Sci Am 202:81-86.

Levine S (1962) Plasma-free corticosteroid response to electric shock in rats stimulated in infancy. Science 135:795-796.

Levine S, Haltmeyer GC, Karas GG, Denenberg VH (1967) Physiological and behavioral effects of infantile stimulation. Physiol Behav 2:55-63.

Lipska BK, Jaskiw GE, Weinberger DR (1993) Postpubertal emergence of hyperresponsiveness to stress and to amphetamine after neonatal excitotoxic hippocampal damage: a potential animal model of schizophrenia. Neuropsychopharmacology 9:67-75.

Ma LJ, Ishizaki Y, Morita I, Murota S (1991) Presence of nitric oxide synthase activity in the neurons of the rat embryonal cerebrum. Neurosci Lett 132:23-25.

Meaney MJ, Aitken DH (1985) The effects of early postnatal handling on the development of hippocampal glucocorticoid receptors: temporal parameters. Dev Brain Res 22:301-304.

Meaney MJ, Aitken DH, Bodnoff SR, Iny LJ, Sapolsky RM (1985a) The effects of postnatal handling on the development of the glucocorticoid receptor systems and stress recovery in the rat. Prog Neuropsychopharmacol Biol Psychiatry 7:731-734.

Meaney MJ, Aitken DH, Bodnoff SR, Iny LJ, Sapolsky RM (1985b) Early, postnatal handling alters glucocorticoid receptor concentrations in selected brain regions. Behav Neurosci 99:760-765.

Meaney MJ, Aitken DH, Sapolsky RM (1987) Thyroid hormones influence the development of hippocampal glucocorticoid receptors in the rat: a mechanism for the effects of postnatal handling on the development of the adrenocortical stress response. Neuroendocrinology 45:278-283.

Meaney MJ, Aitken DH, Bhatnagar S, Van Berkel C, Sapolsky R (1988) Postnatal handling attenuates neuroendocrine, anatomical and cognitive impairments related to the aged hippocampus. Science 238:766-768.

Meaney MJ, Aitken DH, Sharma S, Viau V, Sarrieau A (1989) Postnatal handling increases hippocampal type II glucocorticoid receptors and enhances adrenocortical negative feedback efficacy in the rat. Neuroendocrinology 50:597-604

Meaney MJ, Aitken DHJ, Sharma S, Viau V (1992) Basal ACTH, corticosterone, and corticosterone-binding globulin levels over the diurnal cycle, and hippocampal type I and type II corticosteroid receptors in young and old, handled and nonhandled rats. Neuroendocrinology 55:204-213.

Meaney MJ, Bodnoff SR, O’Donnell D, Rowe W, Sarrieau A, Rose GM, Poirier J, Seckl JR (1993a) Glucocorticoids as regulators of neuron survival and repair, in the aged brain. In: Restorative neurology, Vol 6 (Cuello AC, ed), pp 267-289. Amsterdam: Elsevier.

Meaney MJ, O'Donnell D, Viau V, Bhatnagar S, Sarrieau A, Smythe JW, Shanks N, Walker CD (1993b) Corticosteroid receptors in rat brain and pituitary during development and hypothalamic-pituitary-adrenal (HPA) function. In: Receptors and the developing nervous system (McLaughin P, Zagon I, eds). London: Chapman and Hall.

Medina JH, Izquierdo I (1996) Retrograde messenger, long-term potentiation and memory. Brain Res Rev 21:185-194.

Melzack R, Thompson WR (1956) Effects of early experience on social behavior. Can J Psychol 10:82-90.

Ogilvie P, Schilling K, Billingsley ML, Schmidt HH (1995) Induction and variants of neuronal nitric oxide synthase type I during synaptogenesis. FASEB J 9:799-806.

Pasqualotto BA, Hope BT, Vincent SE (1991) Citrulline in the rat brain: immunocytochemistry and coexistence with NADPH-diaphorase. Neurosci Lett 128:155-160.

Paxinos G, Watson C (1986) The rat brain in stereotaxic coordinates, 2nd edition. San Diego: Academic.
Purpura DP, Pappas GD (1968) Structural characteristics of neurons in the feline hippocampus during postnatal ontogenesis. Exp Neurol 22:379-393.

Radomski MW, Palmer RMJ, Moncada S (1990) Glucocorticoids inhibit the expression of an inducible, but not the constitutive, nitric oxide synthase in vascular endothelial cells. Proc Natl Acad Sci USA 87:10043-10047.

Rakic P, Nowakowski RS (1981) The time of origin of neurons in the hippocampal region of the rhesus monkey. J Comp Neurol 196:99-128.

Roberts GW (1991) Schizophrenia: a neuropathological perspective. Br J Psychiatry 158:8-17.

Roberts GW, Horton K (1992) Neuropathology of psychoses: towards a common biology. In: The temporal lobes and the limbic system (Trimble MR, Bolwig TG, eds), pp 213-238. Petersfield, UK: Wrightson Biomedical.

Sapolsky RM, Krey LC, McEwen BS (1984) Glucocorticoid-sensitive hippocampal neurons are involved in terminating the adrenocortical stress response. Proc Natl Acad Sci USA 81:6174-6177.

Sarrieau A, Sharma S, Meaney MJ (1988) Postnatal development and environmental regulation of hippocampal glucocorticoid and mineralocorticoid receptors in the rat. Dev Brain Res 43:158-162.

Scheibel AB, Kovelman JA (1981) Disorientation of the hippocampal pyramidal cell and its processes in the schizophrenic patient. Biol Psychiatry 16:101-102.

Schmidt HH, Gagne GD, Nakane M, Pollock JS, Miller MF, Murad F (1992) Mapping of neuronal nitric oxide synthase in the rat suggests frequent co-localization with NADPH diaphorase but not with soluble guanylyl cyclase and novel paraneural functions for nitrinergic signal transduction. J Histochem Cytochem 40:1439-1456.

Thompson WR (1957) Influence of prenatal maternal anxiety on emotionality in young rats. Science 125:698-699.

Uemura E, Hartmann HA (1979) RNA content and volume of nerve cell bodies in human brain. II. Subiculum in aging normal patients. Exp Neurol 65:107-117.

Vaid RR, Yee BK, Rawlins JNP, Totterdell S (1996) NADPHdiaphorase reactive pyramidal neurons in Ammon's horn and the subiculum in the rat hippocampal formation. Brain Res 733:31-40.

Valtschanoff JG, Weinberg RJ, Kharazia VN, Nakane M, Schmidt HHHW (1993) Neurons in rat hippocampus that synthesize nitric oxide. J Comp Neurol 331:111-121.

Vincent SR, Kimura H (1992) Histochemical mapping of nitric oxide synthase in the rat brain. Neuroscience 46:755-784.

Vincent SR, Johansson O, Hokfelt T, Skirboll L, Elde RP, Terenius L, Kimmel J, Goldstein L (1983) NADPH-diaphorase: a selective histochemical marker for striatal neurons containing both somatostatin and avian pancreatic polypeptide (APP)-like immunoreactivity. J Comp Neurol 217:252-263.

Wakshlak A, Weinstock M (1990) Neonatal handling reverses behavioral abnormalities induced in rats by prenatal stress. Physiol Behav 48:289-292.

Weber CM, Eke BC, Mainer MD (1994) Differential effects of maternal stress on circulating levels of corticosterone, progesterone, and testosterone in male and female fetuses and their mother. Endocrinology 114:1635-1644.

Weinberger DR (1987) Implications of normal brain development for the pathogenesis of schizophrenia. Arch Gen Psychiatry 44:660-669.

Weiner I, Schnabel I, Lubow RE, Feldon J (1985) The effects of early handling on latent inhibition in male and female rats. Dev Psychobiol 18:291-297.

Weiner I, Feldon J, Ziv-Harris D (1987) Early handling and latent inhibition in the conditioned suppression paradigm. Dev Psychobiol 20:233-240.

Yee BK, Feldon J, Rawlins JNP (1995) Latent inhibition in rats is abolished by NMDA-induced neuronal loss in the retrohippocampal region, but this lesion effect can be prevented by systemic haloperidol treatment. Behav Neurosci 109:227-240. 